Received and accepted: December 20, 2010 DOI: $10.1159 / 000323661$

\title{
Expansion of CD56-Negative, CD16-Positive, KIR-Expressing Natural Killer Cells after T Cell-Depleted Haploidentical Hematopoietic Stem Cell Transplantation
}

\author{
Claudia De Angelis ${ }^{a} \quad$ Antonella Mancusi $^{a} \quad$ Loredana Ruggeri $^{a}$ \\ Marusca Capanni ${ }^{a} \quad E$ Elena Urbani ${ }^{a} \quad$ Andrea Velardi $^{a}$ Martin Stern ${ }^{b}$ \\ ${ }^{a}$ Division of Hematology and Clinical Immunology, Department of Clinical and Experimental Medicine, \\ University of Perugia, Perugia, Italy; ${ }^{b}$ Division of Hematology and Department of Biomedicine, \\ University Hospital Basel, Basel, Switzerland
}

\section{Key Words}

Natural killer cells $\cdot$ Haploidentical hematopoietic stem cell transplantation - Acute myeloid leukemia • Graft-versus-leukemia effect

\begin{abstract}
The main functions of natural killer (NK) cells are early protection against viruses or tumor cells and production of cytokines that regulate immune functions. The present study assessed the role of different NK subsets in exerting graftversus-leukemia effects in recipients of human leukocyte antigen (HLA) haploidentical hematopoietic transplants and monitored for the first time CD3-/CD56- lymphocyte expansion. CD3-/CD56- cells expressed NK cell-associated molecules, such as CD16, NKp46, NKp30, CD244 (2B4), CD161, and killer cell immunoglobulin-like receptors. CD3-/CD56cells further exhibited the classical functional characteristics of NK cells: cytolysis of target cells lacking HLA class I, antibody-dependent cellular cytotoxicity and cytokine production. These results demonstrate that CD56- NK cells are functional, recognize missing self and, like their CD56+ counterparts, may contribute to graft-versus-leukemia reactions.
\end{abstract}

Copyright $\odot 2011$ S. Karger AG, Basel

\section{KARGER}

Fax +41613061234 E-Mail karger@karger.ch www.karger.com
(C) 2011 S. Karger AG, Basel $0001-5792 / 11 / 1261-0013 \$ 38.00 / 0$

Accessible online at: www.karger.com/aha

\section{Introduction}

Natural killer (NK) cells are an important constituent of the innate immune system, exert cytotoxicity against infected and transformed cells, and produce cytokines and chemokines that regulate adaptive immune responses [1-3]. In humans, NK cell function is regulated by clonally distributed inhibitory receptors termed killer cell immunoglobulin-like receptors (KIR). KIR recognize epitopes (KIR ligands) shared by human leukocyte antigen (HLA) class I antigens. Functional NK cells express at least one receptor for self HLA class I. Those which express, as their only inhibitory receptor for self, a KIR for the HLA class I group which is absent on allogeneic targets sense the missing expression of the self class I KIR ligand and mediate alloreactions [4-10].

Donor-versus-recipient NK cell alloreactions may occur in HLA haplotype mismatched (haploidentical) hematopoietic stem cell transplantation (HSCT) with KIR ligand incompatibility in the graft-versus-host direction. NK cell alloreactivity impacts beneficially on outcome after haploidentical transplants $[11,12]$, as it reduces the risk of leukemia relapse without causing graft-versus- 
host disease, and thereby markedly improves leukemiafree survival in humans and in murine models [13-16].

In our studies on the NK cell repertoire reconstitution pattern in haploidentical HSCT recipients, we detected expansion of an unusual KIR-expressing CD16+/CD56- NK cell subset. Here, we describe its phenotype, posttransplant recovery kinetics, function and alloreactive potential.

\section{Materials and Methods}

\section{Patients}

Fifty haploidentical HSCT recipients were included in this study. Approval was obtained from the Umbria Region Ethics Committee and from the Perugia University institutional review board. Informed consent was provided in accordance with the Declaration of Helsinki. Diagnoses were acute myeloid leukemia in 27 patients, acute lymphoblastic leukemia in 12, Hodgkin's lymphoma in 7, non-Hodgkin's lymphoma in 2, chronic myeloid leukemia in 1 and multiple myeloma in 1. Patients received CD34selected peripheral blood hematopoietic stem cell grafts after conditioning with total body irradiation, thiotepa, fludarabine and either antithymocyte globulin or the monoclonal anti-CD3 antibody OKT3. No pharmacological immunosuppression was given after transplantation.

\section{Flow Cytometry and Immunophenotyping}

To study reconstituting NK cell subsets after transplantation we performed immunofluorescence analyses on NK cells purified by the RosetteSep human NK cell enrichment cocktail method (StemCell Technologies, Vancouver, B.C., Canada) which consistently allowed purification of a population $>99 \%$ negative for $\mathrm{CD} 3+\mathrm{T}$ lymphocytes (representative plot in fig. 1a), CD19+ $\mathrm{B}$ lymphocytes, CD66b+ granulocytes and CD36+ monocytes.

To characterize purified NK cells, APC-conjugated anti-CD56 (IgG1; Miltenyi, Bergisch-Gladbach, Germany) was used in combination with either: unconjugated anti-CD16 (IgM; BD Bioscience, San Jose, Calif., USA) developed with fluorescein isothiocyanate (FITC)-conjugated IgM (Southern Biotech, Birmingham, Ala., USA) and phycoerythrin (PE)-conjugated anti-NKp46 (IgG1; Beckman Coulter, Fullerton, Calif., USA); PE-conjugated anti-NKp30 (IgG1; Beckman Coulter); PE-conjugated antiCD244 (2B4, IgG1; eBioscience, San Diego, Calif., USA); PE-conjugated anti-CD161 (NKR-P1A, IgG2a; Miltenyi); (PE)-conjugated anti-KIR2DL2,3/S2, anti-KIR2DL1/S1 and anti-KIR3DL1/S1 (all IgG1 from Beckman Coulter) as well as unconjugated antiNKG2A (IgG2b, kindly donated by A. Moretta, University of Genoa, Italy) developed with FITC-conjugated goat anti-mouse IgG2b antibodies (Southern Biotech); unconjugated anti-NKp80 or unconjugated anti-NKG2D (IgG1, kindly donated by A. Moretta, University of Genoa, Italy) developed with FITC-conjugated goat anti-mouse IgG1 antibodies (Southern Biotech).

Enumeration of $\mathrm{KIR}+/ \mathrm{NKG} 2 \mathrm{~A}-/ \mathrm{CD} 3-/ \mathrm{CD} 56-$ and $\mathrm{KIR}+/$ NKG2A-/CD3-/CD56+ NK cells was determined from peripheral blood mononuclear cells by four-color immunofluorescence using the antibodies described above in conjunction with PECy7-conjugated anti-CD3 (IgG1; eBioscience).
HLA Missing Self-Response and ADCC

To assess missing self-HLA response in CD56+ and CD56NK cells, purified NK cells were incubated with the HLA-deficient erythroleukemia cell line K562. The capacity for ADCC was measured by co-incubating purified NK cells with the EBV-transformed B cell line W00 (which expresses all relevant KIR ligands) in the presence of saturating concentrations of the chimeric IgG anti-CD20 antibody (Rituximab; Roche, Basel, Switzerland). The NK cell response in both assays was measured by assessing IFN- $\gamma$ secretion (by intracellular cytokine staining) and degranulation (by assessing surface CD107a) [17]. As negative controls we coincubated NK cells with autologous phytohemagglutinin (PHA) lymphoblasts (degranulation and IFN- $\gamma$ production $<1 \%$ in both CD56+ and CD56- subsets); positive controls were effector cells with PMA/ionomycin (degranulation and IFN- $\gamma$ production $>30 \%$ in both subsets).

\section{NK Cell Cloning and Cytotoxicity Assay}

NK cells were separated into CD56+ and CD56- subsets by immunomagnetic sorting using PE-conjugated anti-CD56 antibodies and anti-PE antibody-conjugated microbeads (Miltenyi). $\mathrm{Pu}$ rity of subfractions, as assessed by flow cytometry, was $>95 \%$ for CD56+ and $>99 \%$ for CD56- cells. CD56+ and CD56- NK cells were plated in 96-well round-bottom plates at concentrations of 20, 10 and 5 cells/well, activated with PHA (Biochrom KG, Berlin, Germany) and cultured with IL-2 (Chiron BV, Amsterdam, The Netherlands) on irradiated feeder cells for 3 weeks. Specific lysis by cloned NK cells was tested by standard ${ }^{51} \mathrm{Cr}$ release assay using an effector-target ratio of 5:1 against K562 cells, KIR ligand-mismatched allogeneic PHA lymphoblasts, autologous PHA lymphoblasts and leukemic blasts in selected patients. In tests against KIR ligand-mismatched target cells, mean lysis of alloreactive clones only (specific lysis $>5 \%$ ) within the donor's repertoire is reported.

\section{Statistical Analyses}

Characteristics of CD56+ and CD56- NK cells were compared by the Mann-Whitney U test (unpaired comparisons) and Wilcoxon's rank test (paired comparisons), where appropriate. Twosided $p$ values of $<0.05$ were considered statistically significant.

\section{Results}

\section{Identification of NK Subsets Reconstitution in \\ Recipients of Haploidentical Transplantation}

Flow-cytometric analyses of reconstituting NK cells in recipients of T cell-depleted haploidentical HSCT revealed an unusual subset of CD3- lymphocytes expressing KIR but not CD56 molecules (fig. 1b). Upon further investigation, these CD56- cells expressed NK cell-associated and NK cell-specific surface antigens such as CD16, 2B4 (CD244), NKR-P1A (CD161) as well as the natural cytotoxicity receptors NKp30 and NKp46 (fig. 1c-e show representative flow-cytometric plots). Compared to their CD56-expressing counterparts, CD56- NK cells expressed CD16, KIR and CD161 at similar frequencies, 
Fig. 1. Immunophenotype of CD56+ and CD56- NK cells after T cell-depleted haploidentical HSCT. a Detection of a CD56-/ CD3 - population after NK cell purification. b-d Expression of KIR (b), CD16 (c), NKp46 (d) and 2B4 (CD244; e) on CD56and CD56+ NK cells in patients after T cell-depleted haploidentical HSCT. All analyses carried out on RosetteSep-purified NK cells.

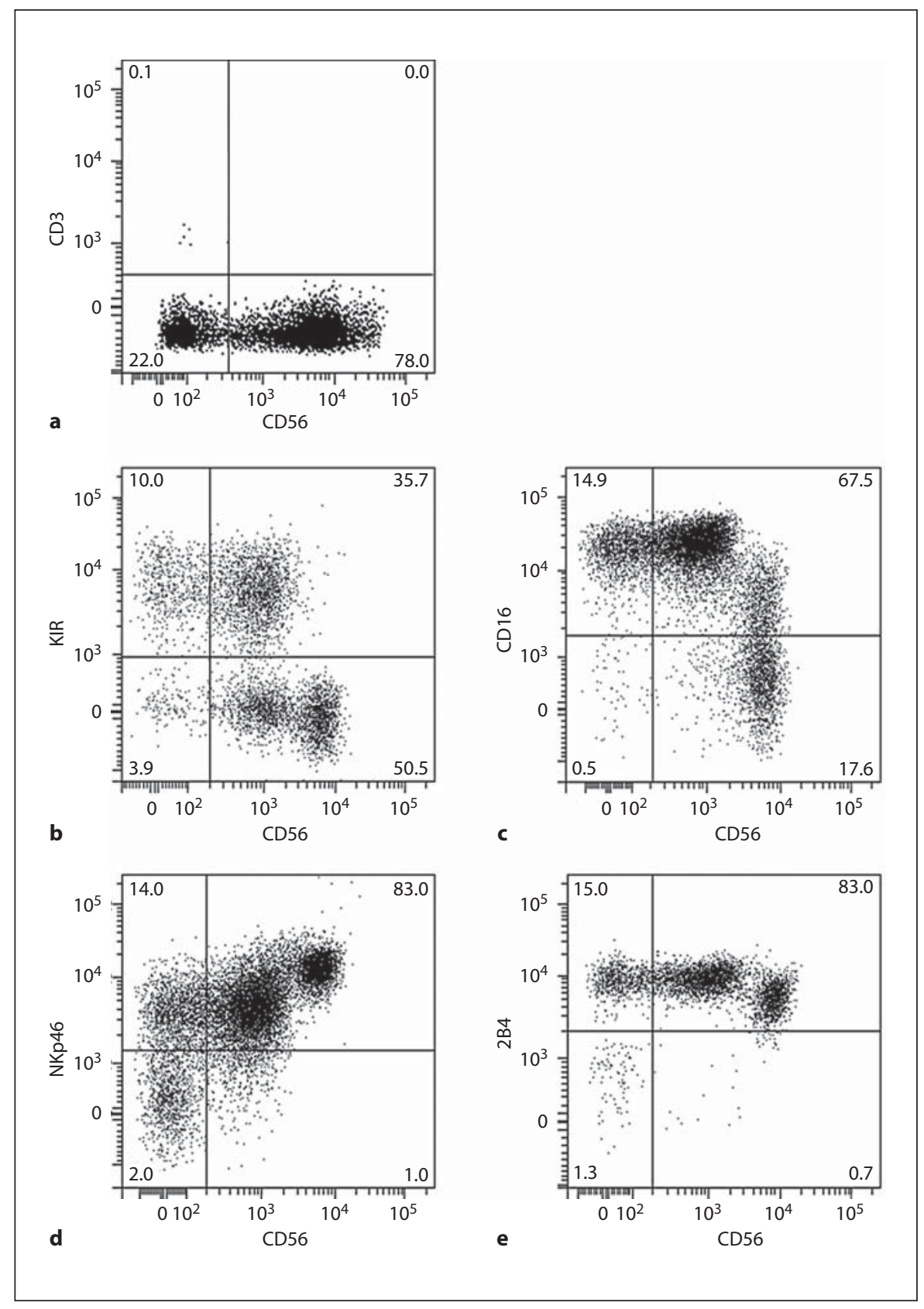

whereas the expression of NKG2A, NKp46, NKp30 and 2B4 was significantly lower in CD56- compared to CD56+ NK cells (table 1).

As expression of multiple KIR identifies a subset of very mature NK cells, we analyzed both overall KIR expression and co-expression of multiple KIR. While overall expression of KIR was similar between the two subsets, expression of more than one KIR was higher in CD56+ NK cells than in CD56- NK cells, although this difference reached statistical significance only for one combination of KIR: KIR2DL1/S1+/KIR2DL2,3/S2+ $(19 \pm 18 \%$ vs. $6 \pm 6.6 \%, \mathrm{p}=0.015)$, KIR2DL2,3/S2+/ KIR3DL1/S1+ (11 $\pm 11 \%$ vs. $3.2 \pm 3 \%, \mathrm{p}=0.06)$ and KIR2DL1/S1+/KIR3DL1/S1+ (5.2 $\pm 4.3 \%$ vs. $1.6 \pm 1.7 \%$, $\mathrm{p}=0.10$ ).

In an attempt to identify a marker that detects the largest possible number of NK cells in transplant recipients, we evaluated several candidate antigens with a broad ex- 


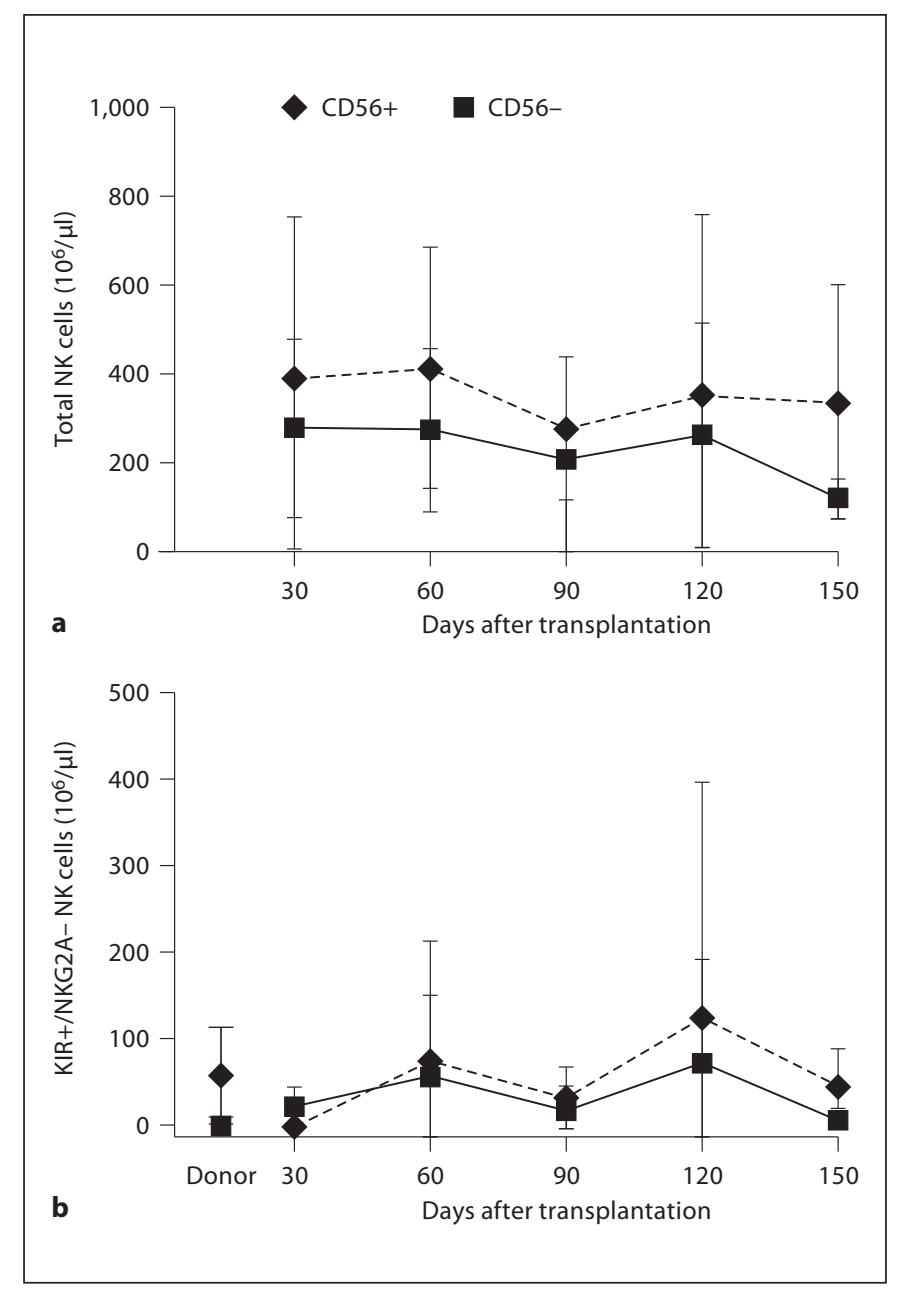

Fig. 2. Post-transplant reconstitution of CD56+ and CD56- NK cells. a Absolute numbers of CD56+ and CD56- NK cells (mean $\pm \mathrm{SD}$ ) in the first 5 months after haploidentical HSCT. b Posttransplant reconstitution of $\mathrm{KIR}+/ \mathrm{NKG} 2 \mathrm{~A}-\mathrm{NK}$ cells in $\mathrm{CD} 56+$ and CD56- subsets (mean $\pm \mathrm{SD}, \mathrm{n}=25$ ).

Table 1. Immunophenotype of NK cells which reconstitute after $\mathrm{T}$ cell-depleted haploidentical transplantation

\begin{tabular}{llll}
\hline Antigen(s) & $\begin{array}{l}\text { CD56+ } \\
\text { NK cells }\end{array}$ & $\begin{array}{l}\text { CD56- } \\
\text { NK cells }\end{array}$ & p value \\
\hline CD16 & $83 \pm 9$ & $82 \pm 12$ & 0.97 \\
KIR & $42 \pm 21$ & $46 \pm 23$ & 0.44 \\
NKG2A & $62 \pm 24$ & $33 \pm 19$ & 0.0001 \\
KIR+/NKG2A- & $38 \pm 24$ & $32 \pm 25$ & 0.02 \\
NKp46 & $82 \pm 19$ & $55 \pm 26$ & 0.0001 \\
NKp30 & $42 \pm 21$ & $35 \pm 20$ & 0.017 \\
CD161 & $68 \pm 27$ & $58 \pm 27$ & 0.11 \\
2B4 & $99 \pm 1$ & $89 \pm 12$ & 0.0001 \\
\hline
\end{tabular}

pression on NK cells. On total NK cells, NKp46 was detected in a mean of $83 \%( \pm 24 \%)$, CD244 (2B4) in $99 \%$ $( \pm 1 \%), \mathrm{NKG} 2 \mathrm{D}$ in $91 \%$ ( $\pm 6 \%)$, and NKp80 in $94 \%( \pm 4 \%)$. Therefore, some of these markers might be more sensitive in detecting NK cells than CD56. For example, CD244 (2B4) was consistently expressed on almost all NK cells at all time points. In contrast, a significant NK cell population lacking the CD56 antigen could be detected up to day 150 after transplant (fig. 2a).

\section{Post-Transplant Reconstitution of KIR+/NKG2A- NK Cells}

As KIR+ NK cells contain the effectors of graft-versusleukemia reactions in haploidentical HSCT, we investigated the kinetics of KIR+/NKG2A- NK cells which emerged after haploidentical HSCT in the CD56+ and the CD56- subsets. At the earliest time point (day 30), CD56-/ KIR+/NKG2A- NK cells outnumbered CD56+/KIR+/ NKG2A- NK cells $\left(33.5 \times 10^{6} \pm 22 \times 10^{6}\right.$ vs. $11 \times 10^{6}$ $\pm 9 \times 10^{6}$ cells $\left./ 1, \mathrm{p}=0.10\right)$. At all later time points the $\mathrm{KIR}+/ \mathrm{NKG} 2 \mathrm{~A}-\mathrm{NK}$ cell count was higher in the CD56+ subset than in the CD56- subset, although the difference did not reach the level of statistical significance (fig. 2b). The KIR+/NKG2A- NK cell count peaked in both the CD56- $\left(85 \times 10^{6} \pm 120 \times 10^{6}\right.$ cells $\left./ \mathrm{l}\right)$ and CD56+ NK cell subsets $\left(136 \times 10^{6} \pm 272 \times 10^{6}\right.$ cells/l, $\left.\mathrm{p}=0.49\right)$ on day 120 and declined thereafter.

\section{Functional Profile of CD56- NK Cells}

To investigate CD56- NK cells functionally, we tested degranulation and cytokine production in response to stimulation with appropriate target cells. Figure 3 a exemplifies degranulation as assessed by surface expression of CD107a after incubation with the HLA-deficient erythroleukemia cell line K562 in CD56- and CD56 ${ }^{\text {dim }}$ NK cells. In agreement with previously published data [18], activation of NK cells by co-incubation with K562 in transplant recipients was lower than that reported for healthy donor NK cells [19]. Degranulation in CD56 dim NK cells $(6 \pm 7 \%)$ was comparable to that of CD56- NK cells $(5 \pm 6 \%, p=0.26$; fig. $3 b)$. In contrast, IFN- $\gamma$ production was significantly lower $(3 \pm 3 \%)$ in CD56- NK cells compared to CD56 ${ }^{\mathrm{dim}} \mathrm{NK}$ cells $(4 \pm 5 \%, \mathrm{p}=0.007$; fig. $3 \mathrm{~b}$ ) after exposure to K562 cells. However, both the degranulation and cytokine production assays suggested that CD56- respond to missing self-stimulation.

In ADCC assays using a B cell line as target cell in conjunction with the anti-CD20 antibody rituximab, $10 \pm$ $5 \%$ of CD56 $6^{\mathrm{dim}} \mathrm{NK}$ cells degranulated compared to $8 \pm$ $5 \%$ of CD56- NK cells $(\mathrm{p}=0.02)$. A similar trend was seen 


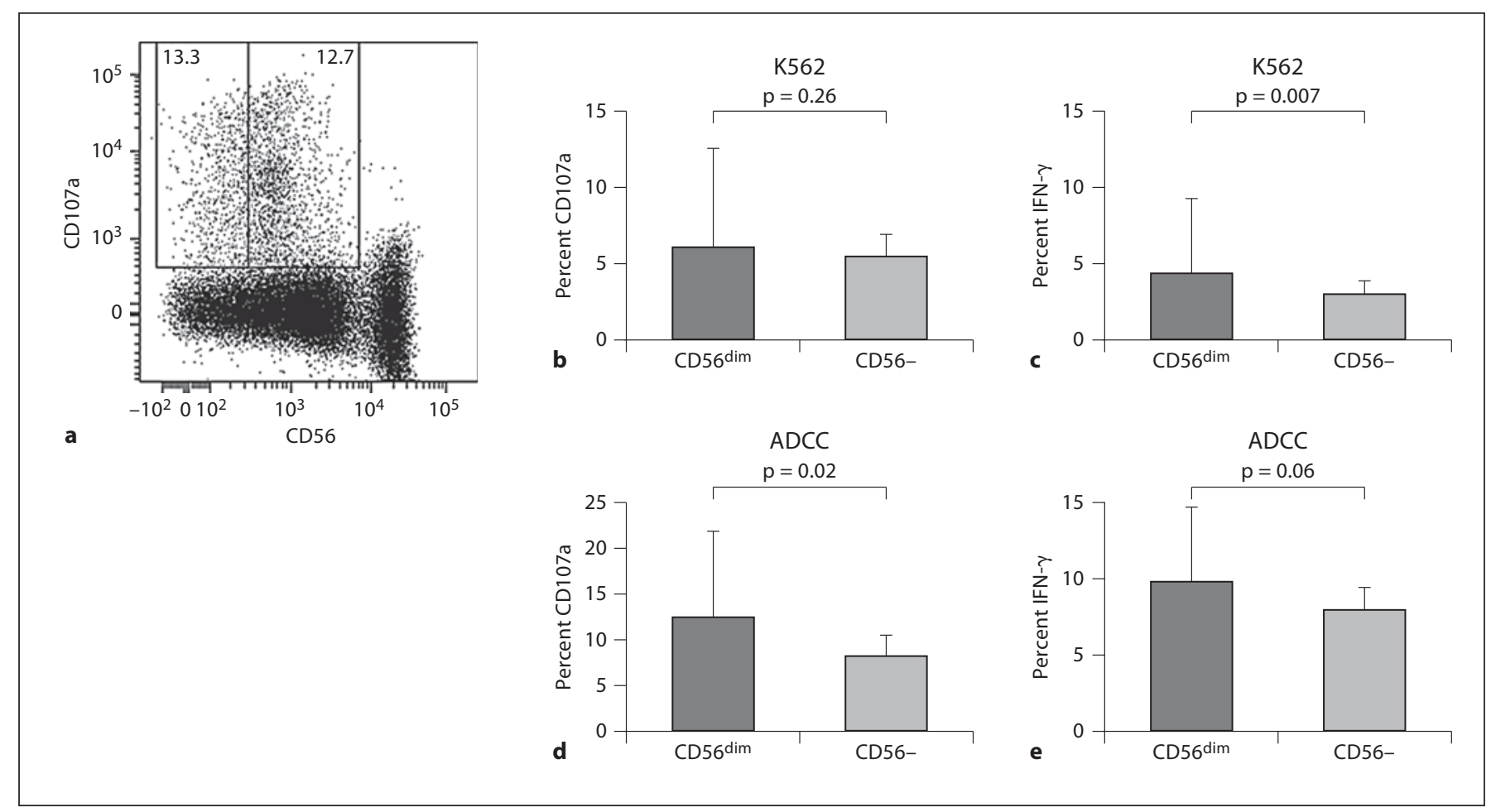

Fig. 3. Functional profile of CD56- NK cells. a Degranulation response (CD107a surface expression) of CD56and CD56 ${ }^{\mathrm{dim}} \mathrm{NK}$ cells after incubation with K562 target cells. CD107a expression and IFN- $\gamma$ production in CD56- and CD56 ${ }^{\mathrm{dim}} \mathrm{NK}$ cells after incubation with $\mathrm{K} 562$ target cells (b, c), and after incubation with the EBVtransformed B cell line in the presence of the anti-CD20 antibody (ADCC; $\mathbf{d}, \mathbf{e})(\mathrm{n}=9$; mean \pm SD).

for IFN- $\gamma$ production which was detected in $12 \pm 10 \%$ of CD56 ${ }^{\mathrm{dim}} \mathrm{NK}$ cells compared to $8 \pm 6 \%$ of CD56- NK cells $(p=0.06$; fig. $3 e)$. No significant degranulation or cytokine production was measured for the CD $56^{\text {bright }} \mathrm{NK}$ cell subset in either assay [20].

\section{Alloreactivity of Clonally Expanded CD56+ and CD56- NK Cells}

Cytotoxicity assays were performed with clonally expanded NK cells against K562 and KIR ligand-mismatched allogeneic targets. Importantly, CD56- NK cells acquired CD56 expression during 15-20 days of stimulation with IL-2, as has previously been shown for CD56NK cells in HIV patients [21]. The proliferative potential of CD56- versus CD56+ NK cells appeared to be similar as indicated by overlapping cloning efficiencies (mean 1 cell in $300, p=0.60$ ) and number of cells obtained for each clone (range $2 \times 10^{5}$ to $4 \times 10^{5}$ ) in the two populations.

Clones derived from CD56+ and CD56- NK cells exerted similar cytotoxicity against K562: $50 \pm 10 \%$ vs. 44 $\pm 17 \%, \mathrm{p}=0.37$ (fig. $4 \mathrm{a}$ ). Alloreactivity was further test- ed against allogeneic targets lacking $\mathrm{C} 1$ or $\mathrm{C} 2$ expression. Lysis of PHA-lymphoblasts lacking HLA-C1 was comparable in 63/383 NK clones derived from CD56+ NK cells (mean lysis $31 \pm 11 \%$ ) and in 57/316 NK clones derived from CD56- NK cells (mean lysis $28 \pm 11 \%, p=0.16$; fig. $4 \mathrm{~b}$ ). In contrast, alloreactivity against allogeneic PHA lymphoblasts lacking HLA-C2 was weaker in 26/340 CD56- NK clones (mean lysis $28 \pm 8 \%$ ) compared to 19/152 CD56+ NK clones (mean lysis $38 \pm 14 \%, \mathrm{p}=$ 0.007 ; fig. 4c). No alloreactive (cytotoxicity $>5 \%$ ) NK clones were detected against KIR ligand-matched targets.

Cryopreserved acute myeloid leukemia blasts were also tested as targets. Alloreactivity against leukemia blasts lacking HLA-C1 was comparable (mean lysis $23 \pm$ $4 \%$ in $6 / 96$ CD56+ NK clones; mean lysis $21 \pm 2 \%$ in 7/165 CD56- NK clones, $\mathrm{p}=0.10$; fig. 4d). Similarly, no significant differences were seen between CD56+ and CD56- NK cell clones in their capacity to lyse leukemia blasts lacking HLA-C2 (mean lysis $20 \pm 1 \%$ ) in 3/107 CD56-NK clones; and mean lysis $22 \pm 1 \%$ in $3 / 93$ CD $56+$ NK clones, $\mathrm{p}=0.65$; fig. $4 \mathrm{e}$ ). 
Fig. 4. Cytolytic activities of clonally expanded CD56- versus CD56+ NK cells. Mean specific lysis of NK clones derived from CD56+ and CD56- NK cells against $\mathrm{K} 562$ target cells (a) and against allogeneic PHA lymphoblasts and leukemic target cells lacking expression of the HLA C1 and C2 specificities $(\mathbf{b}-\mathbf{e})(\mathrm{n}=15)$.

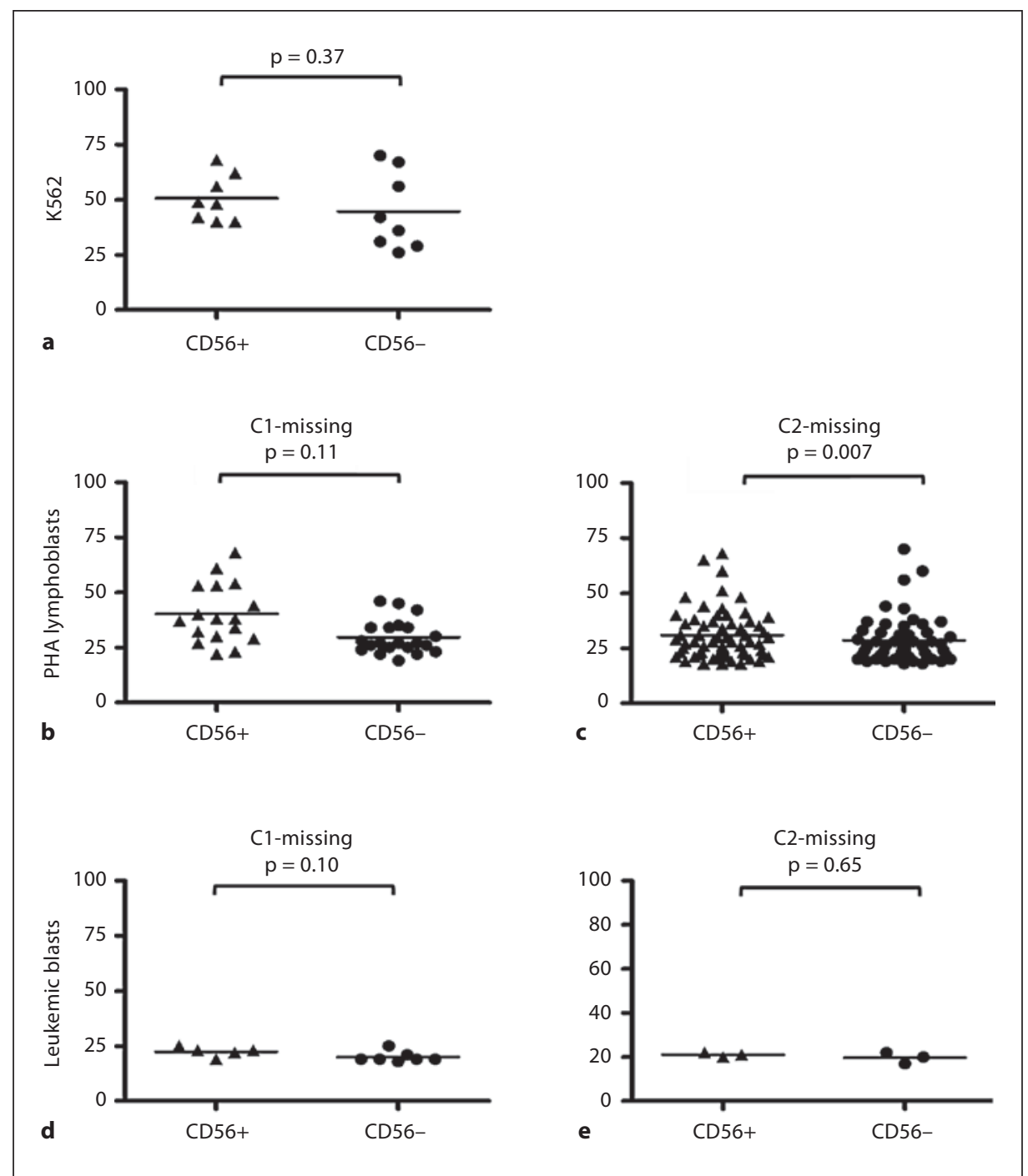

\section{Discussion}

In healthy donors, the majority (approx. 90\%) of NK cells are CD56 ${ }^{\mathrm{dim}}$, whereas approximately $10 \%$ of NK cells are CD56 ${ }^{\text {bright }}$ [1]. NK cells lacking CD56 expression are rare in healthy donors, were originally described in HIVinfected individuals $[21,22]$ and have more recently been found at elevated levels in other chronic infectious diseases, such as hepatitis $C[23,24]$ and Chagas disease [25]. However, in these settings, NK cells lacking CD56 expression are functionally defective as they display decreased levels of activating receptors and fail to kill target cells.

The present study demonstrates that in recipients of $\mathrm{T}$ cell-depleted haploidentical HSCT, a significant number of reconstituting NK cells do not express CD56. We ob- served a remarkable post-transplant expansion of these unusual CD56- NK cells. They express the natural cytotoxicity receptors NKp46 and NKp30 and activating coreceptors such as CD244, lyse HLA-deficient target cells, express KIRs and show cytolytic activity against allogeneic targets and leukemic cells which do not express cognate class I ligands. KIR expression occurs as a late event during NK cell development and NK cells expressing more than one KIR are among the most mature [26, 27]. We found that NK cells expressing more than one KIR were preferentially CD56+. However, our data clearly show that CD56- NK cells are functional. When analyzed at the clonal level, the unusual CD3-/CD56- subset contained similar frequencies of alloreactive NK cells as the conventional CD3-/CD56+ subset. 
An expansion of CD56- NK cells may be common to different forms of HSCT, as CD56-/CD16+ NK cells has previously been described after cord blood transplantation [28], and after HLA-matched bone marrow/peripheral blood stem cell transplantation [29]. Little is known, however, about the function of CD56- NK cells arising after HSCT. Our data suggest that CD56- NK cells may contribute to graft-versus-leukemia effects after haploidentical and possibly other types of HSCT [30].

Finally, the present data have a bearing on recent attempts to assess the frequencies of potentially alloreactive NK cells by flow cytometry [31]. Our data indicate that gating on conventional CD3-/CD56+ cells may considerably underestimate the alloreactive NK cell frequency and that a gating strategy using a more broadly expressed receptor such as CD244 in combination with CD3 may be more appropriate.
In conclusion, we show that in recipients of $\mathrm{T}$ cell-depleted haploidentical HSCT, a significant number of NK cells lack expression of CD56. CD56- NK cells appear to be functional and capable of graft-versus-leukemia effects.

\section{Acknowledgements}

This work was supported by grants from the Italian Association for Cancer Research, the Italian Ministry of Further Education and the Italian Ministry of Health, by the European Union and by a Translational Research Grant from the Leukemia and Lymphoma Society. L.R. is a Leukemia and Lymphoma Society Special Fellow in Clinical Research. A.M. is supported by a fellowship from the Italian Foundation for Cancer Research. M.S. is supported by a research grant from the Swiss National Science Foundation (grant PP00P3-128461/1). We would like to thank Dr. Geraldine Anne Boyd for editorial assistance.

\section{References}

1 Caligiuri MA: Human natural killer cells Blood 2008;112:461-469.

-2 Cooper MA, Fehniger TA, Caligiuri MA: The biology of human natural killer-cell subsets. Trends Immunol 2001;22:633-640.

-3 Trinchieri G: Biology of natural killer cells. Adv Immunol 1989;47:187-376.

4 Karre K: Immunology. A perfect mismatch. Science 2002;295:2029-2031.

5 Ljunggren HG, Karre K: In search of the 'missing self': MHC molecules and NK cell recognition. Immunol Today 1990;11:237244.

-6 Moretta L, Moretta A: Killer immunoglobulin-like receptors. Curr Opin Immunol 2004; 16:626-633.

7 Parham P: Taking license with natural killer cell maturation and repertoire development. Immunol Rev 2006;214:155-160.

-8 Ruggeri L, Aversa F, Martelli MF, Velardi A: Allogeneic hematopoietic transplantation and natural killer cell recognition of missing self. Immunol Rev 2006;214:202-218.

\9 Velardi A, Ruggeri L, Moretta A, Moretta L: NK cells: a lesson from mismatched hematopoietic transplantation. Trends Immunol 2002;23:438-444.

10 Vivier E, Tomasello E, Baratin M, Walzer T, Ugolini S: Functions of natural killer cells. Nat Immunol 2008;9:503-510.

-11 Farag SS, Fehniger TA, Ruggeri L, Velardi A, Caligiuri MA: Natural killer cell receptors: new biology and insights into the graft-versus-leukemia effect. Blood 2002;100:19351947.
12 Ruggeri L, Capanni M, Casucci M, Volpi I, Tosti A, Perruccio K, Urbani E, Negrin RS, Martelli MF, Velardi A: Role of natural killer cell alloreactivity in HLA-mismatched hematopoietic stem cell transplantation. Blood 1999;94:333-339.

13 Ruggeri L, Capanni M, Urbani E, Perruccio K, Shlomchik WD, Tosti A, Posati S, Rogaia D, Frassoni F, Aversa F, Martelli MF, Velardi A: Effectiveness of donor natural killer cell alloreactivity in mismatched hematopoietic transplants. Science 2002;295:20972100.

14 Ruggeri L, Mancusi A, Capanni M, Martelli MF, Velardi A: Exploitation of alloreactive NK cells in adoptive immunotherapy of cancer. Curr Opin Immunol 2005;17:211217.

15 Ruggeri L, Mancusi A, Capanni M, Urbani E, Carotti A, Aloisi T, Stern M, Pende D, Perruccio K, Burchielli E, Topini F, Bianchi E, Aversa F, Martelli MF, Velardi A: Donor natural killer cell allorecognition of missing self in haploidentical hematopoietic transplantation for acute myeloid leukemia: challenging its predictive value. Blood 2007;110:433440.

16 Velardi A, Ruggeri L, Mancusi A, Burchielli E, Perruccio K, Aversa F, Martelli MF: Clinical impact of natural killer cell reconstitution after allogeneic hematopoietic transplantation. Semin Immunopathol 2008;30: 489-503.

17 Alter G, Malenfant JM, Altfeld M: CD107a as a functional marker for the identification of natural killer cell activity. J Immunol Methods 2004;294:15-22.
18 Eissens DN, Schaap NP, Preijers FW, Dolstra $\mathrm{H}$, van Cranenbroek B, Schattenberg AV, Joosten I, van der Meer A: CD3(+)/CD19(+)depleted grafts in HLA-matched allogeneic peripheral blood stem cell transplantation lead to early NK cell cytolytic responses and reduced inhibitory activity of NKG2A. Leukemia 2009.

19 Anfossi N, Andre P, Guia S, Falk CS, Roetynck S, Stewart CA, Breso V, Frassati C, Reviron D, Middleton D, Romagne F, Ugolini S, Vivier E: Human NK cell education by inhibitory receptors for MHC class I. Immunity 2006;25:331-342.

20 Cooper MA, Fehniger TA, Turner SC, Chen KS, Ghaheri BA, Ghayur T, Carson WE, Caligiuri MA: Human natural killer cells: a unique innate immunoregulatory role for the CD56(bright) subset. Blood 2001;97: 3146-3151.

-21 Mavilio D, Lombardo G, Benjamin J, Kim D, Follman D, Marcenaro E, O'Shea MA, Kinter A, Kovacs C, Moretta A, Fauci AS: Characterization of CD56-/CD16+ natural killer (NK) cells: a highly dysfunctional NK subset expanded in HIV-infected viremic individuals. Proc Natl Acad Sci U S A 2005; 102:28862891.

22 Mavilio D, Lombardo G, Kinter A, Fogli M, La Sala A, Ortolano S, Farschi A, Follmann D, Gregg R, Kovacs C, Marcenaro E, Pende D, Moretta A, Fauci AS: Characterization of the defective interaction between a subset of natural killer cells and dendritic cells in HIV-1 infection. J Exp Med 2006;203:23392350. 
>23 Gonzalez VD, Falconer K, Bjorkstrom NK, Blom KG, Weiland O, Ljunggren HG, Alaeus A, Sandberg JK: Expansion of functionally skewed CD56-negative NK cells in chronic hepatitis $\mathrm{C}$ virus infection: correlation with outcome of pegylated IFN-alpha and ribavirin treatment. J Immunol 2009;183:66126618.

-24 Zarife MA, Reis EA, Carmo TM, Lopes GB, Brandao EC, Silva HR, Santana N, MartinsFilho OA, Reis MG: Increased frequency of CD56Bright NK-cells, CD3-CD16+CD56NK-cells and activated CD4+T-cells or Bcells in parallel with CD4+CDC25High Tcells control potentially viremia in blood donors with HCV. J Med Virol 2009;81:49-59.

-25 Vitelli-Avelar DM, Sathler-Avelar R, Dias JC, Pascoal VP, Teixeira-Carvalho A, Lage PS, Eloi-Santos SM, Correa-Oliveira R, MartinsFilho OA: Chagasic patients with indeterminate clinical form of the disease have high frequencies of circulating CD3+CD16CD56+ natural killer $\mathrm{T}$ cells and CD4+ CD25 High regulatory $\mathrm{T}$ lymphocytes. Scand J Immunol 2005;62:297-308.
26 Andersson S, Fauriat C, Malmberg JA, Ljunggren HG, Malmberg KM: KIR acquisition probabilities are independent of selfHLA class I ligands and increase with cellular KIR expression. Blood 2009;114:95-104.

$27 \mathrm{Yu}$ J, Heller G, Chewning J, Kim S, Yokoyama WM, Hsu K: Hierarchy of the Human Natural Killer Cell Response Is Determined by Class and Quantity of Inhibitory Receptors for Self-HLA-B and HLA-C Ligands1. The Journal of Immunology 2007;179:59775989.

28 Lu X, Kondo Y, Takamatsu H, Ohata K, Yamazaki H, Takami A, Akatsuka Y, Nakao S: CD16+ CD56- NK cells in the peripheral blood of cord blood transplant recipients: a unique subset of NK cells possibly associated with graft-versus-leukemia effect. Eur J Haematol 2008;81:18-25.

29 Dunbar EM, Buzzeo MP, Levine JB, Schold JD, Meier-Kriesche HU, Reddy V: The relationship between circulating natural killer cells after reduced intensity conditioning hematopoietic stem cell transplantation and relapse-free survival and graft-versus-host disease. Haematologica 2008;93:1852-1858.
30 Willemze R, Rodrigues CA, Labopin M, Sanz G, Michel G, Socie G, Rio B, Sirvent A, Renaud M, Madero L, Mohty M, Ferra C, Garnier F, Loiseau P, Garcia J, Lecchi L, Kogler G, Beguin Y, Navarrete C, Devos T, Ionescu I, Boudjedir K, Herr AL, Gluckman E, Rocha V: KIR-ligand incompatibility in the graft-versus-host direction improves outcomes after umbilical cord blood transplantation for acute leukemia. Leukemia 2009;23: 492-500.

-31 Vago L, Forno B, Sormani MP, Crocchiolo R, Zino E, Di Terlizzi S, Lupo Stanghellini MT, Mazzi B, Perna SK, Bondanza A, Middleton D, Palini A, Bernardi M, Bacchetta R, Peccatori J, Rossini S, Roncarolo MG, Bordignon C, Bonini C, Ciceri F, Fleischhauer K: Temporal, quantitative, and functional characteristics of single-KIR-positive alloreactive natural killer cell recovery account for impaired graft-versus-leukemia activity after haploidentical hematopoietic stem cell transplantation. Blood 2008;112:3488-3499. 